\title{
Kinetic Studies on the Effect of Salt on the Thermal Denaturation of Egg Constituents
}

\author{
Naomi SHIBATA-ISHIWATARI ${ }^{1}$, Tomoyo TAKAGI ${ }^{2}$, Mika FUKUOKA ${ }^{2,}$, Noboru SAKAI $^{2}$ \\ ${ }^{1}$ Faculty of Education, Gifu University, 1-1, Yanagito, Gifu City, Gifu 501-1193, Japan \\ ${ }^{2}$ Department of Food Science and Technology, Tokyo University of Marine Science and Technology, \\ 4-6-7, Konan, Minato-ku, Tokyo 108-8477, Japan
}

\begin{abstract}
The aim of this study was to investigate the effects of salt on the kinetic parameters of thermal protein denaturation of egg constituents. Egg whites and yolks containing different quantities of added salt were analyzed using differential scanning calorimetry (DSC) and dynamic viscoelastic oscillatory measurements. DSC measurements revealed an increase in the denaturation temperatures of the second peaks of egg whites and yolks in the presence of elevated salt concentrations. Given that the activation energy values obtained from the kinetic analysis of egg proteins using dynamic DSC were comparable, we suggest that salt affects not the denaturation rate of the egg protein, but the temperature of denaturation. Dynamic viscoelastic oscillatory measurements revealed that the gel-point temperatures increased with increasing salt concentrations. The elevated gel-point temperatures coincided with the temperature of the maximum denaturation rate calculated using the kinetic parameters.

Keywords: thermal protein denaturation, egg constituents, kinetic, differential scanning calorimetry, dynamic viscoelasticity
\end{abstract}

\section{Introduction}

Eggs are among the most common and versatile food ingredients, owing to their various functional properties resulting from each of the egg constituents, such as yolks and egg whites and its structures [1]. Several studies have focused on changes in the physicochemical properties of egg constituents during heat treatment and these can be classified into two groups. One is the identification of the denaturation temperature of egg proteins, which are the major components of the egg, using differential scanning calorimetry (DSC) [2-9]. The other focuses on the study of fluctuations of the gel-point temperature and rheological properties using dynamic viscoelastic oscillatory measurements [10-13]. When heated, both egg whites and yolks undergo a continuous phase transition from liquid to semisolid, before finally reaching a solid state. Given the thermal sensitivity of eggs, great attention is given to the temperature of phase conversion. Moreover, since sucrose and salt are frequently added during processing of egg-containing food products $[2,9,11,14]$, many studies have investigated the combined effects of $\mathrm{pH}$, sugar, and salt addition on the gell-

(Received 27 Oct. 2017: accepted 30 Jan. 2018)

† Fax: +81-3-5463-0624, E-mail: fukuoka@kaiyodai.ac.jp ing properties of eggs. As a result of the addition of salt, the aggregation of ovalbumin (the major egg white protein) was found to be significantly increased [9] and the denaturation temperatures of ovotransferrin (another egg white protein) and ovalbumin also increased [3,6] Although several reports have discussed the effects of temperature on rheological properties, little attention has been paid to predicting changes in the physical properties of egg constituents based on kinetic analysis. Since eggs are used for a variety of processed foods, the development of a kinetic model of thermal denaturation during thermal processing is an important challenge for the food industry. If the rate and temperature dependence of a reaction are known, the quality of the food during processing can be easily predicted and controlled. A study by van der Plancken et al. [7] established the kinetic models of egg white proteins and described the physicochemical properties (denaturation enthalpy, surface hydrophobicity, solubility, turbidity, and buried sulfhydryl groups) by a first order fractional conversion model characterized by an end value of property at prolonged heating. This report, however, overlooked the impact of thermal protein denaturation on qualities such as color (appearance) and viscoelastic property (texture). We have reported previously on color change of eggs [15]. The physical properties of egg constituents 
are strongly affected by the degree of protein denaturation and, for this reason, the prediction of protein denaturation during heating is of fundamental importance. Moreover, the previous kinetic model did not consider the effect of added salt. To reliably predict the quality of egg products during heating, it is necessary to consider effects of the addition of salt on the denaturation rate constant. Furthermore, many food products are comprised of multiple components and single purified products are less common. From the perspective of practical applications, it is necessary to perform experiments using intact samples.

In this study, we determined the kinetic parameters of thermal denaturation of intact egg constituents in the presence of salt by using the DSC dynamic method and investigated the effects of the addition of salt on the denaturation rate constant. We also investigated dynamic viscoelasticity, and attempted to predict the physical properties of egg constituents based on thermal denaturation.

\section{Materials and methods}

\subsection{Sample preparation}

Fresh eggs of white leghorn hens (scientific name) were used for each experiment. Eggs were opened manually and the yolk and albumen were separated. After separation, the vitelline membrane was removed and six of each component (whites and yolks) were mixed and homogenized by magnetic stirring at $5^{\circ} \mathrm{C}$. The $\mathrm{pH}$ of the prepared egg white was $8.60 \pm 0.20$.

Egg whites originally contained $0.3 \mathrm{~kg}$ salt/100 kg sample and samples were prepared in the presence of $0.3,0.5,1.0$, and $1.5 \mathrm{~kg}$ salt/100 kg sample. Egg yolk samples were subjected to $10 \%(\mathrm{w} / \mathrm{w})$ dilution with distilled water prior to salt addition. After mixing well, samples were prepared containing $0.5,1.0$, and $1.5 \mathrm{~kg}$ salt/100 kg sample of salt. The salt used was sodium chloride that was obtained from Wako Pure Chemical Industries (Japan). The concentration of sodium chloride in the samples was determined using a salinity concentration meter (SWC-501SA, SANYO Co., Japan).

\subsection{Differential scanning calorimetric measurement}

Each sample of approximately $16 \mathrm{mg}$ was placed in an aluminum sample pan (KIT NO, 0219-0062) and each pan was hermetically sealed. Subsequently, the samples were heated from $25^{\circ} \mathrm{C}$ to $110^{\circ} \mathrm{C}$ at different rates of heating, described by $\beta\left(\beta=5,7.5,10,12.5\right.$, and $\left.15^{\circ} \mathrm{C} / \mathrm{min}\right)$, and measured using a DSC instrument (Pyris1 DSC, Perkin Elmer Inc., USA). An empty pan was used as a reference.

\subsection{Dynamic viscoelastic oscillatory measurements}

The dynamic viscoelastic behavior of egg yolks was measured at a temperature range of $25-95^{\circ} \mathrm{C}$ using a rheometer (HAAKE MARS III; Thermo Fisher Scientific, USA). Samples containing different salt concentrations $(0.5,1.0$, and $1.5 \mathrm{~kg}$ salt $/ 100 \mathrm{~kg}$ sample) were analyzed, and a control with no added salt was used. A $0.5 \mathrm{~mL}$ sample of each concentration was subjected to oscillatory measurements at a frequency of $0.5 \mathrm{~Hz}$ using a $35 \mathrm{~mm}$ parallel plate. The samples were heated at a rate of $1.0^{\circ} \mathrm{C} / \mathrm{min}$ using the Peltier plate of the rheometer. To prevent moisture loss during heating, dimethyl-polysiloxane oil (Shinetsu Kohgyo Co., Japan) was added to the periphery of the measuring plate.

\subsection{Statistical analysis}

A one-way analysis of variance (ANOVA) for significant difference was carried out, and minimum significance was set at $5 \%(p<0.05)$ using the Bonferroni test by Ekuseru-Toukei 2012 (Social Survey Research Information Co., Ltd.).

\subsection{Theory of kinetics of thermal protein denaturation}

When the thermal denaturation rate of a protein is assumed to be proportional to the concentration of nondenatured protein, the reaction kinetics equation is [16]:

$$
\frac{d C}{d t}=-k C
$$

where $k$ is the rate constant of the reaction, $C$ is the concentration of non-denatured protein, and $t$ is time. Eq. (1) is a first-order reaction that is then represented in Eq. (2).

$$
\frac{d}{d t}\left(\frac{C_{t}}{C_{0}}\right)=\frac{d X}{d t}=-k(T) X
$$

where $C_{\mathrm{o}}$ and $C_{\mathrm{t}}$ are the concentration of non-denatured protein at the initial state and at time $t$ and $X$ represents $C_{\mathrm{t}} / C_{0}$ as the non-denaturation ratio, which is a dimensionless variable. The temperature dependence of the reaction rate constant $k$ is represented by the Arrhenius equation:

$$
k=Z \exp \left(-\frac{E_{a}}{R T}\right)
$$

where $Z$ is the pre-exponential factor of the Arrhenius 
equation, $E_{\mathrm{a}}$ is the activation energy, $R$ is the universal gas constant, and $T$ is the temperature.

\section{Results and Discussion}

\subsection{Effect of $\mathrm{NaCl}$ on denaturation temperatures}

Figure 1 shows a typical DSC curve for egg constituents at a heating rate of $15^{\circ} \mathrm{C} / \mathrm{min}$. The egg white sample had two endothermic peaks. From published literature $[2,9]$, the first peak corresponded to ovotransferrin and the second peak corresponded to ovalbumin. Several factors, such as $\mathrm{pH}$ and the presence of salt or sucrose, are known to affect denaturation temperatures [14]. For example, when the salt concentration is higher, the denaturation temperatures of ovotransferrin and ovalbumin are increased $[3,6]$. In our experiment, we were not able to investigate salinity dependence of the first peak, because the first peak temperature was too similar to the second. Only the second peak of egg whites showed salt concentration dependence, probably because our experiments were not performed using purified proteins. Since we used intact samples, the protein concentration in egg whites was likely lower than in purified samples. Interestingly, the egg yolk sample showed the peak maximum temperature of $\sim 85^{\circ} \mathrm{C}$ and our data were similar to those of Huang et al. [5]. As in the second peak of the egg white sample, when the salt concentration was higher, the peak temperature of the egg yolk sample was higher. We were unable to identify the protein detected by DSC, however, because egg yolks are characterized by a complicated structure that include low-density lipoproteins and five kinds of conjugated proteins solubilized in a mixture of water and lipids [17]. Additionally, when the heating rate increased, the peak temperature of all samples increased.

\subsection{Kinetic parameters of protein denaturation obtained by Differential scanning calorimetry dynamic method}

The kinetic analysis of egg proteins during heating cannot be performed without the pre-exponential factor $(Z)$ and the activation energy $\left(E_{\mathrm{a}}\right)$ values. These Arrhenius parameters were estimated using the Ozawa method, wherein DSC analysis was performed under non-isothermal conditions [18]. The observed relationship between the heating rate $\beta$ and $T_{\max }$ during DSC can be demonstrated using the following equation:

$$
\ln \left(\frac{\beta}{T_{\max }^{2}}\right)=\ln \left(\frac{Z R}{E_{a}}\right)-\left(\frac{E_{a}}{R T_{\max }}\right)
$$

With the increase in the heating rate of the scans, the $T_{\max }$ values were observed to shift to higher temperatures. Subsequently, $-\ln \left(\beta / T_{\max }^{2}\right)$ was plotted against $1 / T_{\max }$, according to Eq. (4), in an Ozawa plot. The plots were linear $\left(0.966 \leqq r^{2} \leqq 0.996\right)$ as shown in Fig. 2, and the slopes and intercepts were used to calculate the Arrhenius parameters of each salt concentration. For cured pork meat, Kajitani et al. [19] reported on dependence of the protein denaturation rate constant on salt concentrations. The activation energy of our samples was almost the same as that of cured pork samples, including salt ranges from $2-20 \mathrm{mg} / \mathrm{g}$. Thus, using the averaged activation energy, the empirical equation was represented as the salt concentration dependence of the preexponential factor in the Arrhenius equation and the denaturation rate constant at arbitrary temperatures could be predicted. In our experiment, we assumed that activation energy was independent of salt concentration
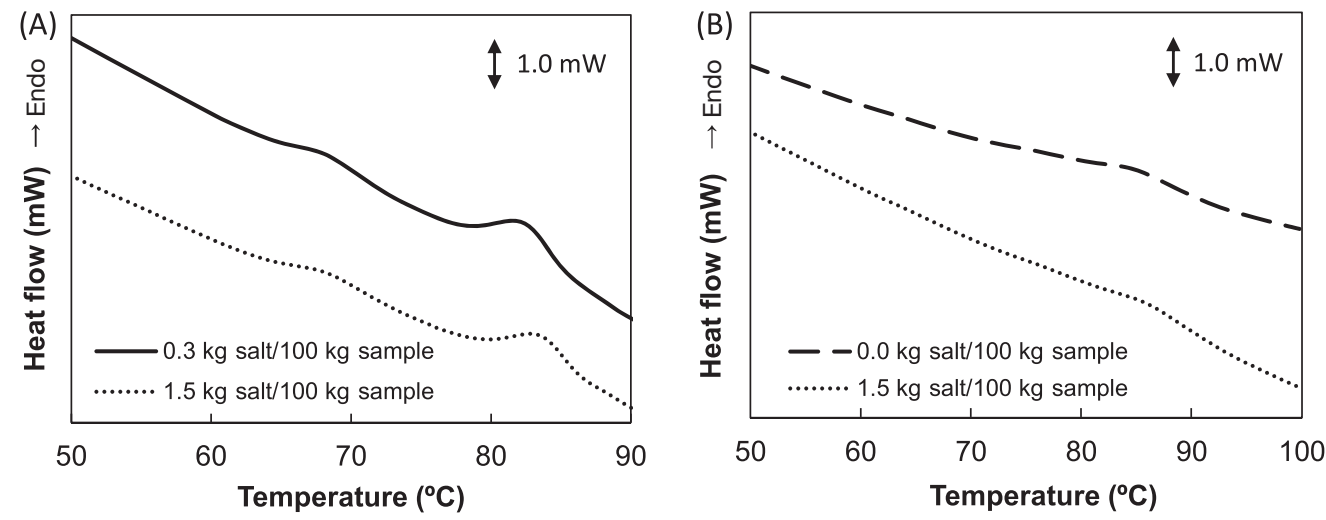

Fig. 1 Differential scanning calorimetry thermogram of egg samples at a heating rate of $15^{\circ} \mathrm{C} / \mathrm{min}$. (A) the thermograms show the concentration of sodium chloride of 0.3 and $1.5 \mathrm{~kg}$ salt/100 $\mathrm{kg}$ sample of egg white, (B) the thermograms show the concentration of sodium chloride of 0.0 and $1.5 \mathrm{~kg}$ salt $/ 100 \mathrm{~kg}$ sample of yolk. 
(A)

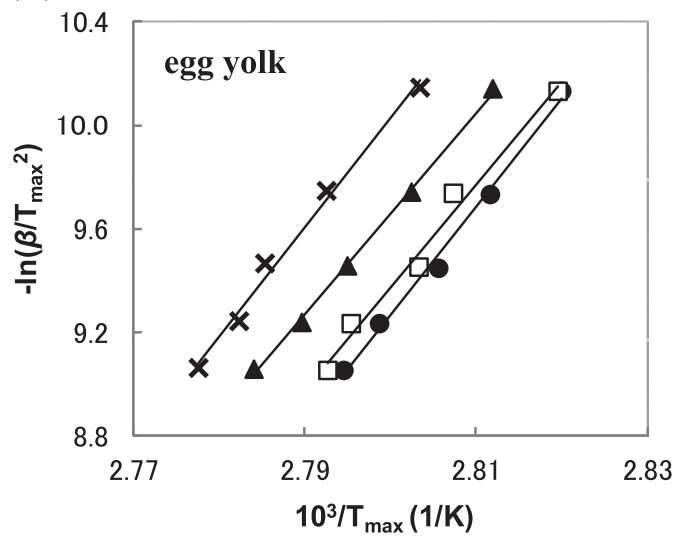

$0.0 \square 0.5 \Delta 1.0 \times 1.5(\mathrm{~kg}$ salt $/ 100 \mathrm{~kg}$ sample $)$

(B)

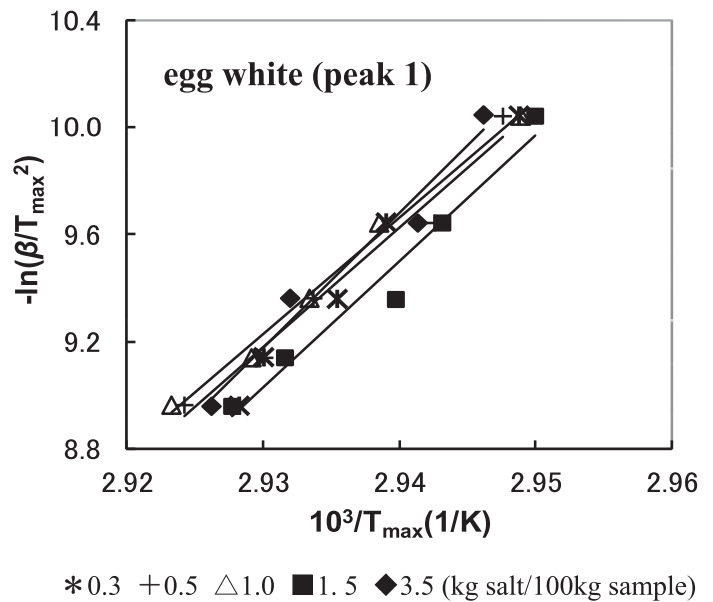

(C)

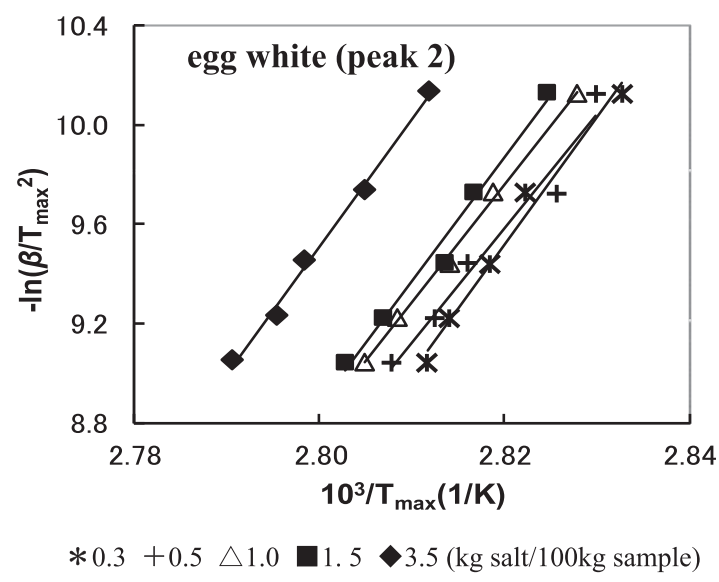

Fig. 2 Ozawa plots of egg yolk (A), egg white (peak1) (B), and egg white (peak2) (C) with varied concentrations of sodium chloride.

because the activation energy was approximately equal for all salt concentrations. The pre-exponential factor of each salt concentration was then calculated using the average of the activation energies. Tables 1 and 2 show the kinetic parameters of each salt concentration calcu- lated in our experiment. In addition, the relationship between the salt concentration and the pre-exponential factor were shown in Fig. 3. For yolks and the second peak of egg whites, the pre-exponential factor may be influenced by the salt concentration. Accordingly, we obtained the following empirical equations for yolks and the second peak of egg whites, as shown in Fig. 3.

For yolks:

$$
y=1.76 \times 10^{59} x^{2}-1.53 \times 10^{60} x+5.06 \times 10^{60}(x \leq 1.5)
$$

For the second peak of egg whites,

$$
y=-9.90 \times 10^{49} x+2.74 \times 10^{50}(0.3 \leq x \leq 3.5)
$$

where $x$ is the salt concentration ( $\mathrm{kg}$ salt/100 kg sample), and $y$ is the pre-exponential factor $\left(Z, \min ^{-1}\right)$.

The pre-exponential factor of the first peak of egg whites exhibited an irregularly fluctuating behavior with

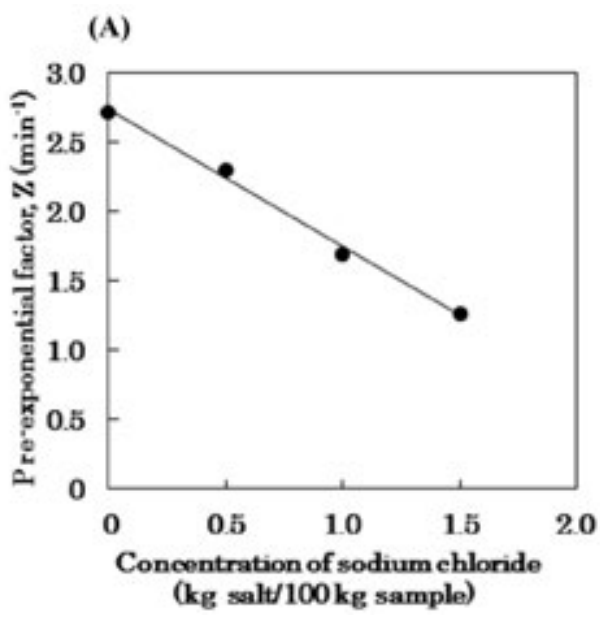

(B)

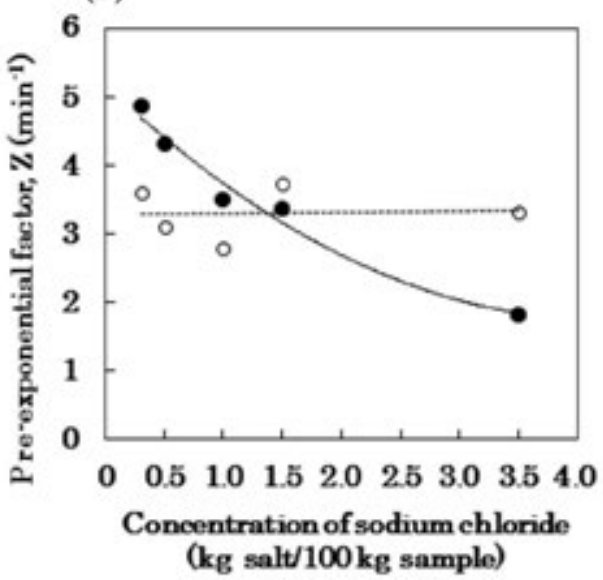

Fig. 3 The relationship between the pre-exponential factor, $Z$, and the sodium chloride concentration of egg yolk (A), and egg white (B). For the egg white $(B),(\bigcirc)$ and (๑) corresponds to the first peak and the second peak, respectively. The solid line represents an empirical equation, Eq. (5) and (6). The dotted line represents the average $Z$ value for the first peak of egg white. 
Table 1 Kinetic parameters for each salt concentration used in egg white samples. The activation energy value was averaged for all salt concentrations.

\begin{tabular}{|c|c|c|c|c|c|c|c|}
\hline & & & \multicolumn{5}{|c|}{ Concentration of sodium chloride (kg salt/100 kg sample) } \\
\hline & & & 0.3 & 0.5 & 1.0 & 1.5 & 3.5 \\
\hline \multirow{2}{*}{ egg white } & Peak 1 & $\begin{array}{c}\mathrm{E}_{\mathrm{a}}{ }^{*}(\mathrm{~kJ} / \mathrm{mol}) \\
\mathrm{Z}(1 / \mathrm{min})\end{array}$ & $3.61 \times 10^{60}$ & $3.11 \times 10^{60}$ & $\begin{array}{c}390.6 \pm 36.3 \\
2.79 \times 10^{60}\end{array}$ & $3.72 \times 10^{60}$ & $3.31 \times 10^{60}$ \\
\hline & Peak 2 & $\begin{array}{c}\mathrm{E}_{\mathrm{a}}^{*}(\mathrm{~kJ} / \mathrm{mol}) \\
\mathrm{Z}(1 / \mathrm{min})\end{array}$ & $4.85 \times 10^{60}$ & $4.13 \times 10^{60}$ & $\begin{array}{c}407.9 \pm 20.0 \\
3.50 \times 10^{60}\end{array}$ & $3.36 \times 10^{60}$ & $1.83 \times 10^{60}$ \\
\hline
\end{tabular}

* Mean \pm standard deviation of $E_{a}$

Table 2 Kinetic parameters for each salt concentration used in egg yolk samples. The activation energy value was averaged for all salt concentrations.

\begin{tabular}{ccccc}
\hline & \multicolumn{5}{c}{ Concentration of sodium chloride (kg salt/100 kg sample) } \\
& 0.0 & 0.5 & 1.0 & 1.5 \\
\hline $\mathrm{E}_{\mathrm{a}}^{*}(\mathrm{~kJ} / \mathrm{mol})$ & \multicolumn{4}{c}{$340.5 \pm 12.2$} \\
$\mathrm{Z}(1 / \mathrm{min})$ & $2.72 \times 10^{50}$ & $2.30 \times 10^{50}$ & $1.70 \times 10^{50}$ & $1.27 \times 10^{50}$ \\
\hline
\end{tabular}

${ }^{*}$ Mean \pm standard deviation of $E_{a}$

changes in salt concentration as shown in Fig. 3(B). It was difficult to represent salt concentration dependence. Thus, assuming that the pre-exponential factor was independent of the salt concentration, the following average value ( average $Z=3.31 \times 10^{60}$ ) was calculated using all preexponential factors with varied salt concentrations.

Regarding protein denaturation kinetics using the DSC dynamic method, beef [20,21], pork [19], and fish samples [22-23] were reported. Given that the calculated value in our study was similar to more than one other reference [22-23], the calculated parameter is likely applicable for the prediction of the denaturation rate of egg proteins. Thus, the activation energy and the pre-exponential factor were determined and the protein kinetics of thermal denaturation at an arbitrary temperature could be calculated according to Eqs. (2) and (3) with Eq. (6), and average $Z$.

Figure 4(A) shows the calculated changes in the nondenaturation ratio of egg white samples during heating from $25^{\circ} \mathrm{C}$ to $110^{\circ} \mathrm{C}$ at a heating rate of $10^{\circ} \mathrm{C} / \mathrm{min}$. Peak I began to denature at approximately $55^{\circ} \mathrm{C}$. Peak II did not undergo denaturation until the denaturation of peak I was complete, even at temperatures close to $72^{\circ} \mathrm{C}$. When the course of protein denaturation was differentiated according to time, the inflection point that corresponded to the peak temperature for the DSC measurements could be obtained. Figure 4(B) shows the inflection point for each salt concentration. These values were nearly equal to the $T_{\max }$ value obtained by DSC; thus, we considered the kinetic parameters determined using the DSC dynamic method to be reliable. Figure 5 shows the dena-
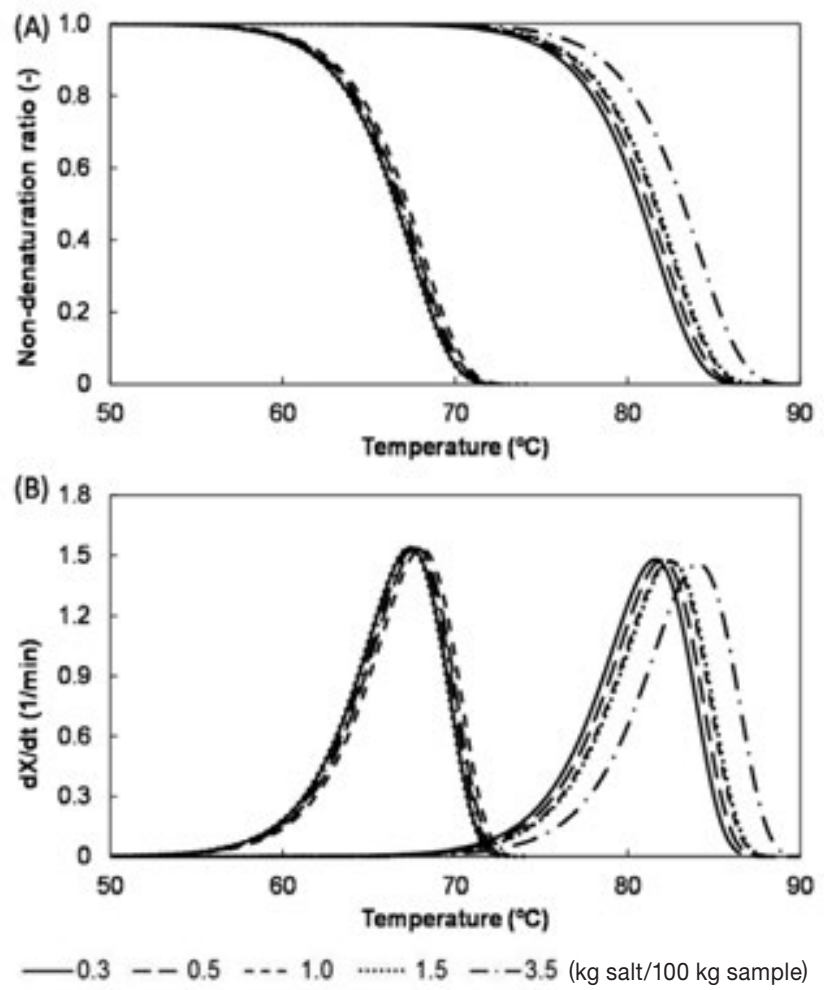

Fig. 4 Calculation results of egg whites. (A) Calculated changes of the non-denaturation ratio during heat-scanning at $10^{\circ} \mathrm{C} /$ min. (B) When the time course of protein denaturation was differentiated with time, the inflection point corresponding to the peak temperature in DSC measurement could be obtained.

turation behavior of the egg yolk during heating from $25^{\circ} \mathrm{C}$ to $110^{\circ} \mathrm{C}$ at a heating rate of $10^{\circ} \mathrm{C} / \mathrm{min}$. Figure $5(\mathrm{~A})$ depicts how the proteins of the egg yolk began to denature at approximately $70^{\circ} \mathrm{C}$ and that denaturation was completed at $\sim 90^{\circ} \mathrm{C}$. Moreover, when the salt concentra- 


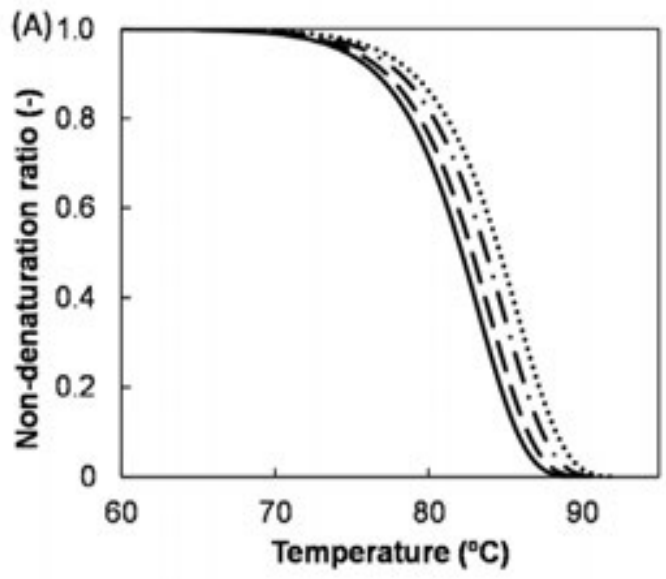

$-0.0-0.5$

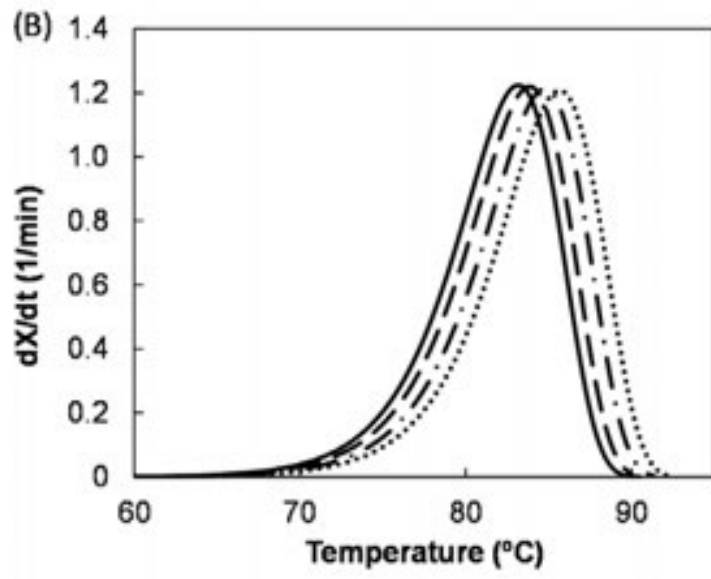

1.5 (kg salt/100 kg sample)

Fig. 5 Calculation results of yolks: (A) calculated changes of the non-denaturation ratio during heat-scanning at $10^{\circ} \mathrm{C} / \mathrm{min}$, (B) when the time course of protein denaturation was differentiated with time, the inflection point corresponding to the peak temperature in DSC measurement could be obtained.

tion was higher, the denaturation temperature of egg yolks and the second peak of egg whites increased. In addition, Fig. 4(B) and Fig. 5(B) show that the fastest rate of protein denaturation was the same and the similarity in the relationship between the changes does not depend on salt concentration. Thus, we think that the addition of salt increased the denaturation temperature, but had no significant effect on the rate of denaturation. Moreover, we have shown that the degree of protein denaturation can be controlled by modulating salt concentrations and heat-treatments.

\subsection{Relationship between dynamic}

\section{viscoelasticity and protein denaturation} during temperature scanning

Figure 6 represents typical changes in the storage

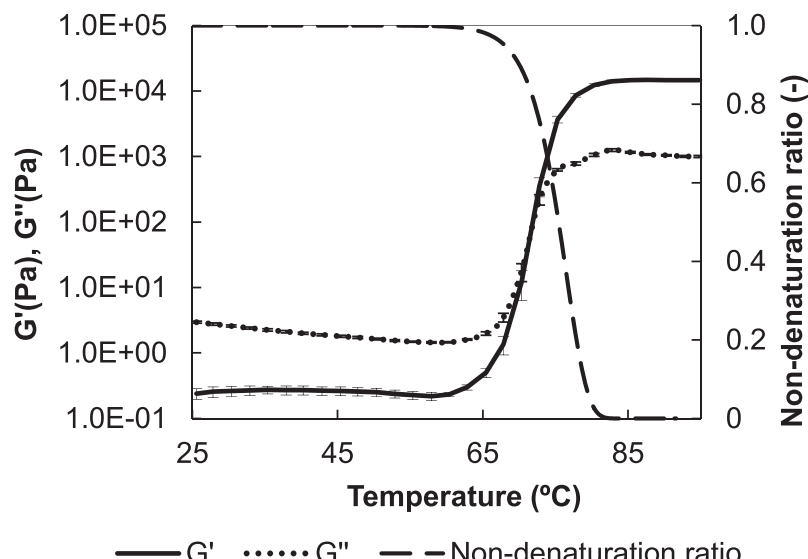

Fig. 6 Comparison of the changes in storage modulus, loss modulus, and prediction of the non-denaturation ratio of yolk

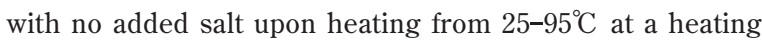
rate of $1.0^{\circ} \mathrm{C} / \mathrm{min}$. modulus G' and the loss modulus G" of egg yolk without salt and with temperature scanning (over $25-95^{\circ} \mathrm{C}$ ) at a rate of $1.0^{\circ} \mathrm{C} / \mathrm{min}$. The relationship between $\mathrm{G}^{\prime}, \mathrm{G}^{\prime}$, and temperature can be classified into three stages. In the first stage $\left(25-65^{\circ} \mathrm{C}\right)$, because $\mathrm{G}$ ” was higher than $\mathrm{G}$, the sample was more viscous than elastic. Subsequently, both values increased markedly $\left(65-80^{\circ} \mathrm{C}\right)$, until $\mathrm{G}^{\prime}$ exceeded G” at $70.8^{\circ} \mathrm{C}$. Finally, G” exceeded G', and the property of the yolk became elastic. When the temperature reached $80^{\circ} \mathrm{C}$, both values reached equilibrium. This pattern was similar in the samples that contained salt. Table 3 shows the gel-point temperature based on the values measured for each salt concentration. The gelpoint temperature was determined as the $\mathrm{G}^{\prime}-\mathrm{G}$ " crossover point [24]. Table 3 suggests that the addition of salt was effective in delaying gelling because the gel-point temperature was significantly elevated with increasing salt concentrations $(p<0.05)$. Raikos et al. [11] measured the gelling point of intact yolk using a rheometer. The

Table 3 Relations between salt concentration and gel-point temperature in egg yolk samples analyzed by dynamic viscoelastic oscillatory measurements.

\begin{tabular}{cc}
\hline $\begin{array}{c}\text { Concentration of sodium chloride } \\
\text { (kg salt/100 kg sample) }\end{array}$ & Gel-point $\left({ }^{\circ} \mathrm{C}\right)$ \\
\hline 0.0 & $70.5 \pm 0.29^{\mathrm{a}}$ \\
0.5 & $71.7 \pm 0.19^{\mathrm{b}}$ \\
1.0 & $72.6 \pm 0.30^{\mathrm{c}}$ \\
1.5 & $73.7 \pm 0.32^{\mathrm{d}}$ \\
\hline
\end{tabular}

Each value is the mean \pm standard deviation. Different letters in the same row indicate significant difference between means $(p<$ $0.05)$. 
gelling temperature of the sample in the absence of salt was $72.3 \pm 0.18^{\circ} \mathrm{C}$ and was approximately equal to that found in our experiment $\left(70.5 \pm 0.29^{\circ} \mathrm{C}\right)$. The change in temperature range undergone by $\mathrm{G}^{\prime}$ and $\mathrm{G}$ " was remarkably similar to the denaturation temperature found for the egg yolk samples; after proteins denatured completely, both values reached equilibrium values (Fig. 6) These results suggest a close relationship between the degree of protein denaturation and rheological properties. Moreover, the temperature at which the rate of protein denaturation was the fastest is $71.2^{\circ} \mathrm{C}$ and was found to be approximately equal to the gel-point temperature $\left(70.5 \pm 0.29^{\circ} \mathrm{C}\right)$. In the case of an egg white sample with no added salt, the temperature of the fastest rate of denaturation of peak II was $76.5^{\circ} \mathrm{C}$, which was calculated at a heating rate of $1.0^{\circ} \mathrm{C} / \mathrm{min}$ using the kinetic parameters shown in Table 1. This calculated temperature was almost the same as the gel-point temperature measured by Raikos et al. [11]. In a previous study [25], we proposed that the new empirical model could predict the viscosity of expressible water in meat, based on the denaturation kinetics of water-soluble proteins combined with Andrade's equation. Although the previous model focused on the change in viscosity during heating, the prediction of phase conversion was not taken into account. Given the extensive use of egg-containing food products in the food industry, not only the change of protein denaturation ratio, but also predictions of phase conversion are highly important. In this study, in the case of yolks and the second peak of egg whites, we found that the gel-point temperature and the temperature of the maximum denaturation rate were approximately the same and we could predict the phase conversion based on the rate of protein denaturation. We think that the prediction of protein denaturation using kinetic parameters is essential to estimate rheological properties.

\section{Conclusions}

We determined the kinetic parameters of the thermal denaturation of egg constituents, which were separated into egg whites and yolks, in the presence of salt, using the DSC dynamic method. In addition, we verified the correlation between protein denaturation and change of property based on dynamic viscoelasticity.

1. We assumed that the activation energy was independent of the salt concentration and the pre-exponential factor of each salt concentration was calculated using the average activation energy;
2. In the case of yolks and the second peak of egg whites, when the salt concentration increased, the pre-exponential factor was higher and could be represented with an empirical equation;

3. From prediction results, we think that the addition of salt increased the denaturation temperature, but had no effect on the rate of protein denaturation;

4. In case of the yolk and the second peak of egg whites, because the gel-point temperature and the temperature of the maximum denaturation rate were approximately the same, the phase conversion could be predicted based on the rate of denaturation of proteins.

Our work suggests that the prediction of protein denaturation using kinetic parameters is a valuable tool to estimate the rheological properties of a wide range of egg constituents.

\section{NOMENCLATURE}

$C \quad$ : concentration of non-denatured protein, $\mathrm{mol} \cdot \mathrm{g}^{-1}$

$C_{0}$ : initial concentration of non-denatured protein, $\mathrm{mol} \cdot \mathrm{g}^{-1}$

$C_{\mathrm{t}}:$ concentration of non-denatured protein at time $t$, $\mathrm{mol}^{-1}$

$E_{\text {a }}:$ activation energy in the Arrhenius equation, $\mathrm{kJ} \cdot \mathrm{mol}^{-1}$

$k$ : rate constant of the reaction, $\min ^{-1}$

$R \quad$ : gas constant, $\mathrm{kJ} \cdot \mathrm{mol}^{-1}$

$T$ : temperature, ${ }^{\circ} \mathrm{C}$

$T_{\max }$ : maximum peak temperature, ${ }^{\circ} \mathrm{C}$

$X$ : non-denaturation ratio, -

$Z$ : pre-exponential factor in the Arrhenius equation, $\min ^{-1}$

$\beta \quad$ : heating rate, ${ }^{\circ} \mathrm{C} \cdot \mathrm{min}^{-1}$

\section{References}

1) Y. Mine; Recent advances in the understanding of egg white protein functionality. Trends Food Sci. Tech., 6, 225-232 (1995).

2) R. Nakamura, I. Omori; Protective effect of some anions on the heat-denaturation of ovotransferrin. Agric. Biol. Chem., 43, 2393-2394 (1979).

3) J. I. Boye, A. A. Ismail, B. F. Gibbs, Y. Konishi; Factors affecting molecular characteristics of whey protein gelation. Int Dairy J., 5, 337-53 (1995).

4) S. L. Chung, L. K. Ferrier; Heat denaturation and emulsifying properties of egg yolk phosvitin. J. Food Sci., 60, 906908, 916 (1995). 
5) S. Huang, D. D. Mueller; Effect of electron beam irradiation on physical, physicochemical, and functional properties of liquid egg during frozen storage. Poultry Sci., 76, 16071615 (1997).

6) K. Mizutani, Y. Chen, H. Yamashita, M. Hirose, S. Aibara; Thermostabilization of ovotransferrin by anions for pasteurization of liquid egg white. Biosci. Biotech. Bioch., 70, 1839-1845 (2006).

7) I. van der Plancken, A. van Loey, M. E. Hendrickx; Effect of heat-treatment on the physico-chemical properties of egg white proteins: A kinetic study. J. Food Eng., 75, 316-326 (2006).

8) E. Ibanoglu, E. A. Ercelebi; Thermal denaturation and functional properties of egg proteins in the presence of hydrocolloid gums. Food Chem., 101, 626-633 (2007).

9) S. J. Choi, T. W. Moon; Influence of sodium chloride and glucose on the aggregation behavior of heat-denaturated ovalbumin investigated with a multiangle laser light scattering technique. J. Food Sci., 73, C41-C49 (2008).

10) N. Ogawa, T. Hisatsuka, K. Watanabe; Rheological and microstructural studies on heat - induced gels of thick and thin egg white from fresh and stored shell egg. J. Cookery Sci. Jpn, 35, 148-155 (2002).

11) V. Raikos, L. Campbell, S. R. Euston; Rheology and texture of hen's egg protein heat-set gels as affected by $\mathrm{pH}$ and the addition of sugar and/ or salt. Food Hydrocolloid., 21, 237244 (2007).

12) A. Laca, B. Paredes, M. Diaz; A method of egg yolk fractionation. Characterization of fractions. Food Hydrocolloid., 24, 434-443 (2010).

13) A. Laca, B. Paredes, M. Diaz; Thermal behaviour of lyophilized egg yolk and egg yolk fractions., J. Food Eng., 102, 77-86 (2011).

14) A. M. Hermansson; Soy protein gelation. J. American Oil Chemist's Soci., 63, 658-666 (1986).

15) Y. Llave, S. Fukuda, M. Fukuoka, N. Shibata-Ishiwatari, N. Sakai; Analysis of color changes in chicken egg yolks and whites based on degree of thermal protein denaturation during ohmic heating and water bath treatment. J. Food Eng., 222, 151-161 (2018).

16) R. Villota, J. G. Hawkes; "Reaction kinetics in Food Systems. In Handbook of Food engineering, second edition”, D. R. Heldman, D. B. Lund, eds., CRC Press, 2007, pp.125-286.

17) K. Nagao; Changes in thermal conduction and mechanical properties of foodstuffs accompanying phase transitions during heating. J. Home Econ. Jpn., 55, 837-844 (2004).

18) T. Ozawa; Kinetic analysis of derivative curves in thermal analysis. J. Thermal. Anal., 2, 301-324 (1970).

19) S. Kajitani, M. Fukuoka, N. Sakai; Kinetics of thermal denaturation of protein in cured pork meat. Jpn. J. Food Eng., 12, 19-26 (2011).

20) J. R. Wagner, M. C. Anon; Denaturation kinetics of myfibrillar proteins in bovine muscle. J. Food Sci., 50, 1547-1551 (1986).

21) N. Ishiwatari, M. Fukuoka, N. Sakai; Effect of protein denaturation degree on texture and water state of cooked meat, J. Food Eng., 117, 361-369 (2013).

22) X. Yu, Y. Llave, M. Fukuoka, N. Sakai; Estimation of color changes in fish surface at the beginning of grilling based on the degree of protein denaturation. J. Food Eng., 129, 12-20 (2014).

23) Y. Llave, N. Shibata-Ishiwatari, M. Watanabe, M. Fukuoka, N. Hamada-Sato, N. Sakai; Analysis of the effects of thermal protein denaturation on the quality attributes of sous-vide cooked tuna. J. Food Process. Preserv. doi. org/10.1111/jfpp.13347 (2017).

24) X. D. Sun, S. D. Arntifield; Dynamic oscillatory rheological measurement and thermal properties of pea protein extracted by salt: Effect of pH and $\mathrm{NaCl}$. J. Food Eng., 105, 577582 (2011).

25) N. Shibata-Ishiwatari, M. Fukuoka, N. Sakai; Changes in the viscosity of expressible water in meat during heating: Description based on the denaturation kinetics of watersoluble proteins. Food Sci. Tech. Res., 21, 525-530 (2015). 